\section{GSK and UC make up}

\section{By Lev Osherovich, Senior Writer}

GlaxoSmithKline plc and the University of California have reconciled their differences related to whether researchers at the 10-campus system can participate in GSK's Discovery Fast Track program. The University of California technology transfer offices will now vet applications for potentially sensitive disclosures before the pharma lays eyes on them.

GSK launched Discovery Fast Track in May to allow academic researchers to form collaborations with the pharma to test diseaserelated hypotheses. ${ }^{1}$

Under the original terms of the precompetitive program, prospective participants were asked to submit brief, nonconfidential disclosures to the pharma about their scientific ideas and plans for collaboration with GSK.

The program hit a snag when the technology transfer office of the University of California, Los Angeles barred researchers at that campus from participating. ${ }^{2}$ That policy soon was widened to cover the entire UC system.

Brendan Rauw, associate vice chancellor and executive director of entrepreneurship at the UCLA Office of Intellectual Property and Industry Sponsored Research, said there was concern about the potential for disclosure of confidential information and conflict with third-party rights to the researchers' discoveries.

In June, GSK conducted discussions with Rauw and representatives of the UC Office of General Counsel and came up with a fix.
Under the modified terms of participation in the Discovery Fast Track program, technology transfer offices will electronically monitor submissions and disclosures by researchers at their campuses. The goal is to ensure nothing confidential is disclosed to the pharma.

"The opportunity to review applications beforehand was a critical part of the agreement," said Rauw. "We wanted to ensure that our staff was involved in the process. Our oversight is now required."

"We always intended for the investigators to engage their own technology transfer offices," said Pearl Huang, VP and global head of GSK's Discovery Academic Partnerships (DPAc) unit, which runs the Discovery Fast Track program. "We heard from multiple offices that they were concerned about ensuring their engagement. We're now able to make sure that happens."

One concern about UC's efforts to vet contacts between academia and industry is that slow turnaround by technology transfer offices can delay collaborative research.

Rauw said the amended terms of the program require technology transfer offices to review Discovery Fast Track applications "on a tight time frame."

According to the program's website, technology transfer offices will have five days to review applications after the submission deadline, which is July 19.

If the technology transfer office fails to sign off by the deadline, the applications will be discarded.

Going forward, GSK will use the IP vetting system it set up at UC's request for all participants in the Discovery Fast Track program, not just those at UC campuses.

Osherovich, L. SciBX 6(27); doi:10.1038/scibx.2013.674

Published online July 18, 2013

\section{REFERENCES}

1. Osherovich, L. SciBX 6(10); doi:10.1038/scibx.2013.230

2. Osherovich, L. SciBX 6(22); doi:10.1038/scibx.2013.536

\section{COMPANIES AND INSTITUTIONS MENTIONED}

GlaxoSmithKline plc (LSE:GSK; NYSE:GSK), London, U.K.

University of California, Oakland, Calif.

University of California, Los Angeles, Calif. 